Research Article

\title{
Nanosized Zincated Hydroxyapatite as a Promising Heterogeneous Photo-Fenton-Like Catalyst for Methylene Blue Degradation
}

\author{
Van Dat Doan, ${ }^{1}$ Van Thuan Le $\mathbb{B}^{2},{ }^{2}$ Thi Thanh Nhi Le, ${ }^{2}$ and Hoai Thuong Nguyen $\mathbb{i}^{3,4}$ \\ ${ }^{1}$ Faculty of Chemical Engineering, Industrial University of Ho Chi Minh City, Ho Chi Minh City, Vietnam \\ ${ }^{2}$ Center for Advanced Chemistry, Institute of Research \& Development, Duy Tan University, Danang, Vietnam \\ ${ }^{3}$ Division of Computational Physics, Institute for Computational Science, Ton Duc Thang University, Ho Chi Minh City, Vietnam \\ ${ }^{4}$ Faculty of Electrical \& Electronics Engineering, Ton Duc Thang University, Ho Chi Minh City, Vietnam
}

Correspondence should be addressed to Hoai Thuong Nguyen; nguyenhoaithuong@tdtu.edu.vn

Received 21 January 2019; Accepted 28 March 2019; Published 24 April 2019

Guest Editor: Dinh Quang Khieu

Copyright (C) 2019 Van Dat Doan et al. This is an open access article distributed under the Creative Commons Attribution License, which permits unrestricted use, distribution, and reproduction in any medium, provided the original work is properly cited.

\begin{abstract}
This study is devoted to synthesis of nanosized zincated hydroxyapatite (Zn-HA) and its utilization as a heterogeneous photoFenton-like catalyst for degradation of methylene blue (MB) in aqueous solution. The prepared catalyst was characterized by various techniques such as $\mathrm{X}$-ray diffraction, scanning electron microscopy, transmission electron microscopy, energy-dispersive $\mathrm{X}$-ray, and Fourier transform infrared spectroscopy. The catalytic activity of Zn-HA towards MB and the effects of various experimental factors such as $\mathrm{pH}$, zinc substitution degrees, initial $\mathrm{MB}$ concentration, and $\mathrm{H}_{2} \mathrm{O}_{2}$ dosage were studied in detail. The results showed that the zinc substitution degree of 0.4 is optimal to get the highest degradation efficiency under conditions of $\mathrm{pH}=10, \mathrm{H}_{2} \mathrm{O}_{2}$ dosage of $0.05 \mathrm{M}$, and $\mathrm{MB}$ concentration of $30 \mathrm{mg} / \mathrm{L}$ for a contact time of $120 \mathrm{~min}$. The degradation mechanism was proposed and discussed thoroughly. Besides, the ability of long-term use for the synthesized catalyst was also evaluated.
\end{abstract}

\section{Introduction}

The rapid industrialization with developing various kinds of chemical-based industries leads to several major environmental issues caused by a huge amount of toxic substances discharged into ecosystems. In this context, persistent organic pollutants as dyes must be taken into account due to their high toxicity and nonbiodegradability under normal conditions [1-4]. Recently, an examination conducted in Singapore in 2017 reported that essential everyday foods such as vegetables, canned meat, fruits, and cheese in local supermarkets contained at least one type of azo dyes which might cause several health problems as lethal, genotoxic, mutagenic, and carcinogenic effects [5]. Thus, removal of toxic dyes from contaminated sources is extremely important and attracts a great attention from the global scientific community.

Up to now, there have been several methods used for removal of organic pollutants such as flocculation, ion- exchange, reverse osmosis, adsorption, etc. [6-8]. A major drawback of these methods is related to the secondary polluted compounds that can be generated since the separated pollutants are not destroyed after detoxification $[9,10]$. To overcome this barrier, heterogeneous Fentonphotocatalysis has been utilized to remove organic pollutants by degrading them into eco-friendly biodegradable substances $[11,12]$. In this photocatalysis, properties of photocatalysts play a leading role in ensuring success of a treatment process. In this regard, many kinds of Fentonphotocatalysts have been developed. Among them, heterogeneous photocatalysts containing transition metals such as $\mathrm{Fe}, \mathrm{Cu}, \mathrm{Zn}, \mathrm{Mn}, \mathrm{Co}, \mathrm{Mn}$, and Ti are widely used due to their high photocatalytic activity and low cost $[11,13]$. However, these materials exhibit a good performance mostly in UV region, but not under a wide spectrum of visible light due to the limits of their band gaps [14-16]. Moreover, most of the methods used to modify band gaps for improving 
photocatalytic activity of catalysts are quite expensive and complicated [17-20].

Recently, several studies have been made on using hydroxyapatite $\left(\mathrm{Ca}_{10}\left(\mathrm{PO}_{4}\right)_{6}(\mathrm{OH})_{2}-\mathrm{HA}\right)$, a main mineral constituent of mammalian hard tissues, as a supporting material for improving photocatalytic activity of catalysts because of its biocompatibility and excellent adsorption capacity and photocatalytic activity for removal of both organic compounds and toxic heavy metals [21-24]. With regards to photocatalytic activity, Valizadeh et al. have successfully synthesized magnetite-hydroxyapatite for photocatalytic degradation of acid blue 25 [24]. Besides, another research group [25] used waste mussel shells to develop HA as a greener and renewable photocatalyst for the degradation of methylene blue (MB) [25]. Although the photocatalytic capacity of HA is not higher than those of metal-oxide photocatalysts, cost benefits, ecofriendliness, simple preparation, and reusability are huge advantages of this material. Especially, the structure of $\mathrm{HA}$ can be modified because its cations $\mathrm{Ca}^{2+}$ and functional groups of $\mathrm{PO}_{4}{ }^{3-}$ and $\mathrm{OH}^{-}$are easily replaced by other ions, and therefore, its photocatalytic potential can be intervened. For example, $\mathrm{Fe}_{3} \mathrm{O}_{4}$-hydroxyapatite modified by $\mathrm{Mn}, \mathrm{Fe}, \mathrm{Co}, \mathrm{Ni}, \mathrm{Cu}$, and $\mathrm{Zn}$ as reported in [26] exhibited very high photocatalytic capability towards dyes in water under UV irradiation. However, there have been several drawbacks that are needed to overcome. Firstly, the $\mathrm{Fe}_{3} \mathrm{O}_{4}$ and hydroxyapatite components were physically linked to each other, leading to the low stability of material structure during a long-term treatment process. Secondly, the used metals were distributed mainly inside $\mathrm{Fe}_{3} \mathrm{O}_{4}$-hydroxyapatite structure, but not on its surface due to the substitution of $\mathrm{Ca}^{2+}$ by metals ions took place mainly at lattice points $[26,27]$. As a result, $\mathrm{Fe}_{3} \mathrm{O}_{4}$-hydroxyapatite could not be able to exhibit its full photocatalytic potential.

Based on the above arguments, this study is devoted to using chemical precipitation method to develop a singlephase $\mathrm{Zn}-\mathrm{HA}$ as a heterogenous photo-Fenton-like catalyst for $\mathrm{MB}$ degradation. For this material, $\mathrm{Zn}$ is integrated into $\mathrm{HA}$ via anion substitution of $\mathrm{PO}_{4}{ }^{3-}$ by $\mathrm{Zn}(\mathrm{OH})_{4}{ }^{2-}$. Crystalline structure, morphology, features of functional groups, and element analysis of $\mathrm{Zn}-\mathrm{HA}$ were carefully characterized using XRD, SEM, TEM, FTIR, and EDX techniques. Besides, the optimal conditions for degradation of MB were also determined. Finally, the reusability was also evaluated for the long-term of the catalyst.

\section{Materials and Methods}

2.1. Reagents and Materials. Calcium hydroxide $\left(\mathrm{Ca}(\mathrm{OH})_{2}\right.$, $\geq 96 \%)$, phosphoric acid $\left(\mathrm{H}_{3} \mathrm{PO}_{4}, 85 \%\right)$, sodium hydroxide $(\mathrm{NaOH}, 99 \%)$, zinc oxide $(\mathrm{ZnO}, 99 \%), \mathrm{MB}\left(\mathrm{C}_{16} \mathrm{H}_{18} \mathrm{ClN}_{3} \mathrm{~S}\right.$, $\geq 82 \%$ ), hydrogen peroxide $\left(\mathrm{H}_{2} \mathrm{O}_{2}, 30 \%\right)$, and ammonium hydroxide $\left(\mathrm{NH}_{4} \mathrm{OH}, 30 \%\right)$ were reagent-grade, supplied by Merck chemical company (Germany), and used without further purification. Distilled water was used to prepare all necessary solutions for the synthesis of $\mathrm{Zn}-\mathrm{HA}$.
2.2. Preparation of $\mathrm{Zn}-\mathrm{HA}$ Catalyst. The Zn-HA samples were synthesized by the chemical precipitation method from solutions of $\mathrm{Na}_{2} \mathrm{Zn}(\mathrm{OH})_{4}, \mathrm{Ca}(\mathrm{OH})_{2}$, and $\mathrm{H}_{3} \mathrm{PO}_{4}$. The solution of $\mathrm{Na}_{2} \mathrm{Zn}(\mathrm{OH})_{4}$ was prepared by adding gradually $0.2 \mathrm{M}$ $\mathrm{NaOH}$ solution into a suspension of $0.05 \mathrm{M} \mathrm{ZnO}$ until a clear solution was obtained. The solutions of $0.02 \mathrm{M} \mathrm{Ca}(\mathrm{OH})_{2}$ and $\mathrm{H}_{3} \mathrm{PO}_{4} 10 \%$ were prepared from pure solid of $\mathrm{Ca}(\mathrm{OH})_{2}$ and concentrated solution of $\mathrm{H}_{3} \mathrm{PO}_{4} 85 \%$, respectively. For the synthesis of $\mathrm{Zn}-\mathrm{HA}$, the solution of $\mathrm{H}_{3} \mathrm{PO}_{4} 10 \%$ was slowly added drop by drop into a reactor containing $\mathrm{Na}_{2} \mathrm{Zn}(\mathrm{OH})_{4}$ and $\mathrm{Ca}(\mathrm{OH})_{2}$ with vigorous stirring for $1 \mathrm{~h}$. The solutions were taken out at different $\mathrm{Ca}: \mathrm{P}: \mathrm{Zn}$ ratios of $9: 6: 0 ; 9: 5.9$ : $0.1 ; 9: 5.75: 0.25 ; 9: 5.6: 0.4 ; 9: 5.4: 0.55 ;$ and $9: 5.3: 0.65$ named as HA, Zn-HA-0.1, Zn-HA-0.25, Zn-HA-0.4, Zn-HA0.55 , and Zn-HA- 0.65 , respectively. The $\mathrm{pH}$ of obtained solutions was kept at $\mathrm{pH} \geq 10$ using $\mathrm{NH}_{4} \mathrm{OH}$. After the reactions finished, the mixtures were left for aging at room temperature for $24 \mathrm{~h}$ and then filtered, washed, dried, crushed, and pulverized through a 100 -mesh sieve.

2.3. Characterization of Catalysts. X-ray powder diffraction (XRD) on a Shimadzu 6100 diffractometer (Japan) with $\mathrm{Cu}$ target $(\lambda=1.5406 \AA)$, accelerating voltage of $40 \mathrm{kV}$, and current stream of $30 \mathrm{~mA}$ in a scanning range from 5 to $90^{\circ}$ at a speed of $0.05^{\circ} / \mathrm{s}$ with a step size of $0.02^{\circ}$ was used to explore structural properties of materials. The features of functional groups were analyzed by Fourier transform infrared spectroscopy (FTIR) technique on a Tensor 27 spectrophotometer (Germany) in a scanning range from $500-4000 \mathrm{~cm}^{-1}$ using $\mathrm{KBr}$ pellet method. The morphology of materials was tested by the methods of scanning electron microscopy (SEM) and transmission electron microscopy (TEM) on Jeol JSM-6480 LV and Jeol 1400 (Japan) microscopes, respectively. Finally, energy-dispersive X-ray (EDX) and element mapping techniques were utilized on a Horiba 7593 dispersive X-ray microanalyzer (Japan) to analyze the chemical elemental characteristics of the obtained materials.

2.4. Experiments for $M B$ Degradation. The photo-Fenton catalytic potential of the as-prepared $\mathrm{Zn}-\mathrm{HA}$ composite was evaluated through the degradation of $\mathrm{MB}$ as a model azo dye. A certain amount of catalyst was dispersed into $100 \mathrm{~mL}$ of $\mathrm{MB}$ solution $(20,30,50,80,100 \mathrm{mg} / \mathrm{L})$ and stirred in the dark for $30 \mathrm{~min}$ to reach adsorption-desorption equilibrium between $\mathrm{MB}$ and catalyst. Then, a calculated amount of $\mathrm{H}_{2} \mathrm{O}_{2}$ was added into the suspension to initiate the reaction under light irradiation turned on at the same time from $250 \mathrm{~W}$ halogen lamp (HLX 64653; Osram, Germany, wavelength range of $300-800 \mathrm{~nm}$ ) equipped with a $420 \mathrm{~nm}$ cut-off filter. Besides, a thermostatic water-bath was employed to keep the reaction temperature at a desired value. In addition, the initial $\mathrm{pH}$ of $\mathrm{MB}$ solutions was adjusted to a desired value using $0.1 \mathrm{M} \mathrm{NaOH}$ or $0.1 \mathrm{M} \mathrm{HCl}$ solutions. After each 10minute contact time, $2 \mathrm{~mL}$ of the mixture was taken out, the catalyst was then eliminated by centrifugation, and the remaining $\mathrm{MB}$ concentration was analyzed using an Evolution $600 \mathrm{UV}$-visible spectrophotometer at $\lambda_{\max }=664 \mathrm{~nm}$. The influence of factors as initial $\mathrm{pH}$, catalyst dosage, initial 
hydrogen peroxide dosage, $\mathrm{MB}$ concentration, and zinc content on the MB degradation was carefully examined. The efficiency for degradation of MB using $\mathrm{Zn}-\mathrm{HA}$ is calculated by the following formula:

$$
R_{\mathrm{e}}=\frac{C_{0}-C_{\mathrm{f}}}{C_{0}} \cdot 100
$$

where $R_{\mathrm{e}}(\%)$ is the removal efficiency and $C_{0}(\mathrm{mg} / \mathrm{L})$ and $C_{\mathrm{f}}(\mathrm{mg} / \mathrm{L})$ are the initial and final concentrations of $\mathrm{MB}$ solution before and after degradation, respectively.

Photocatalytic stability and reusability of the catalysts were evaluated by testing the photocatalytic degradation efficiency of $\mathrm{MB}$ in five consecutive cycles, each cycle lasted $60 \mathrm{~min}$. After each cycle, the photocatalyst was centrifuged and then added again into fresh $\mathrm{MB}$ solution $(100 \mathrm{~mL}$, $50 \mathrm{mg} / \mathrm{L}, \mathrm{pH}$ of $10, \mathrm{H}_{2} \mathrm{O}_{2}$ dosage of $0.05 \mathrm{M}$ ) for the next round.

\section{Results and Discussion}

3.1. Characterization of the Catalyst. The results for study on crystalline structures of HA and Zn-HA with different $\mathrm{Zn}$ content are shown in Figure 1.

It is obviously seen that the XRD patterns of Zn-HA samples contain all characteristic peaks for HA at $2 \theta$ of 10.8 , 25.7, 28.2, 29.1, 31.7, 32.8, 39.7, 46.9, 48, 49.5, and 53.1 (ICD PDF 00-024-0033). In other words, the zinc doping did not affect crystalline structure of HA. Similar results were also reported in previous studies [28-30]. However, as compared to the HA, the peaks obtained for $\mathrm{Zn}-\mathrm{HA}$ are broadened. This might be due to the decrease in the crystallinity and particle size of the Zn-HA sample [30]. Besides, the XRD patterns also indicated that there were additional phases of $\mathrm{Ca}(\mathrm{OH})_{2}$ and $\mathrm{CaCO}_{3}$ detected in $\mathrm{Zn}-\mathrm{HA}$ samples at a zinc substitution degree higher than 0.4 (Figure 1). This anomaly can be explained as follows. The increase in the amount of $\mathrm{Zn}(\mathrm{OH})_{4}{ }^{2-}$ (which was made by the dissolution of $\mathrm{ZnO}$ in $\mathrm{NaOH}$ as described above) in the reaction mixture of $\mathrm{Ca}(\mathrm{OH})_{2}$ and $\mathrm{H}_{3} \mathrm{PO}_{4}$ led to the shortage of $\mathrm{H}_{3} \mathrm{PO}_{4}$ due to its neutralization by $\mathrm{NaOH}$ and therefore resulting in the superabundance of $\mathrm{Ca}(\mathrm{OH})_{2}$. At the same time, a part of extra $\mathrm{Ca}(\mathrm{OH})_{2}$ could react with $\mathrm{CO}_{2}$ in atmosphere to form $\mathrm{CaCO}_{3}$.

The morphology of HA and $\mathrm{Zn}-\mathrm{HA}$ at $\mathrm{Zn}$-substitution degree of 0.4 is presented in Figure 2. It can be seen that the crystals of HA were grown in needle shape with 150-200 nm length and $30-50 \mathrm{~nm}$ width (Figure 2(a)) while Zn-HA crystals have a spherical shape with a diameter of about $20 \mathrm{~nm}$ (Figure 2(b)). The difference of size and shape between HA and $\mathrm{Zn}$-HA might be associated with the increased number of crystallization centers when $\mathrm{Zn}(\mathrm{OH})_{4}{ }^{2-}$ was added into the reaction mixture of $\mathrm{Ca}(\mathrm{OH})_{2}$ and $\mathrm{H}_{3} \mathrm{PO}_{4}$. Consequently, more crystals might be formed, leading to the decrease in their size. This is also in good agreement with the above XRD patterns. It should be noticed that the smaller the size of crystals, the larger the specific surface area obtained. This feature is an advantage of $\mathrm{Zn}$-HA over HA towards photocatalytic ability. On a larger-scale view as shown in SEM images (Figures 2(c) and 2(d)), both HA and Zn-HA show a similar morphology.

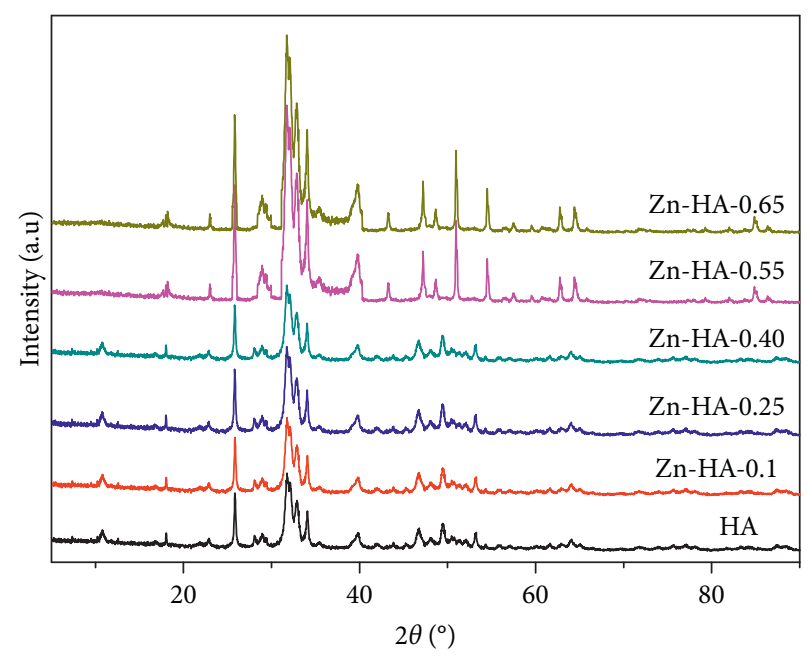

FIGURE 1: XRD patterns of HA and Zn-HA samples with different Zn content.

The doping of $\mathrm{Zn}$ into HA was also confirmed by EDX spectra and element mapping as shown in Figure 3. According to the EDX spectrum for Zn-HA (Figure 3(b)), along with the main elements characteristic for HA such as $\mathrm{Ca}, \mathrm{P}$, and $\mathrm{O}$ (Figure 3(a)), $\mathrm{Zn}$ was detected. Besides, the contents of $\mathrm{Ca}, \mathrm{P}$, and $\mathrm{O}$ elements in $\mathrm{HA}$ and $\mathrm{Zn}-\mathrm{HA}$ are different. Comparing with $\mathrm{HA}$, the content of $\mathrm{P}$ and $\mathrm{O}$ in $\mathrm{Zn}$ HA was found to decrease from 13.77 to $2.41 \mathrm{w} \%$ and 59.97 to $50.01 \mathrm{w} \%$, respectively. Meanwhile, the Ca content increased from 23.81 to $44 \%$ equal to the $\mathrm{Ca}$ content in stoichiometric HA. It obviously indicated that $\mathrm{PO}_{4}{ }^{3-}$ groups in HA were partially replaced by $\mathrm{Zn}(\mathrm{OH})_{4}{ }^{2-}$. Moreover, the element mapping shows also the appearance of 4 elements of $\mathrm{Ca}, \mathrm{Zn}, \mathrm{O}$ and $\mathrm{P}$ on $\mathrm{Zn}-\mathrm{HA}$ (Figures 3(c)-3(f)). In addition, the even distribution of $\mathrm{Zn}$ ions on $\mathrm{Zn}-\mathrm{HA}$ surface (Figure 3(d)) is expected to improve photocatalytic activity of the synthesized catalyst as compared to those of HA.

The results for study on features of functional groups for $\mathrm{HA}$ and $\mathrm{Zn}-\mathrm{HA}$ with different $\mathrm{Zn}$ content are shown in Figure 4. It is obviously seen that FTIR spectra obtained for $\mathrm{HA}$ and $\mathrm{Zn}$-HA have a similar shape and most of characteristic peaks as $1030,1085,956$, and $874 \mathrm{~cm}^{-1}$ referred to $\mathrm{OH}^{-}$were detected at the same positions. Besides, the presence of $\mathrm{CO}_{3}{ }^{2-}$ as mentioned above was also detected at 1650 and $1423 \mathrm{~cm}^{-1}$. However, a difference of intensity between some peaks in HA and Zn-HA was observed. Specifically, for Zn-HA samples, the intensity of a peak at $3640 \mathrm{~cm}^{-1}\left(\mathrm{OH}^{-}\right.$groups) was found to be increased and at $1030 \mathrm{~cm}^{-1}\left(\mathrm{PO}_{4}{ }^{3-}\right.$ groups) decreased in comparison with those for HA, confirming the successful integration of $\mathrm{Zn}(\mathrm{OH})_{4}{ }^{2-}$ into HA structure.

3.2. Photo-Fenton Catalytic Activity of the Catalysts. In order to evaluate the photocatalytic advantage of $\mathrm{Zn}-\mathrm{HA}$ over HA, a comparative study was conducted under the same experimental conditions of light irradiation, $\mathrm{pH}=10$, and catalyst loading of $0.1 \mathrm{~g}$ added into $100 \mathrm{~mL}$ of $50 \mathrm{mg} \cdot \mathrm{L}^{-1} \mathrm{MB}$ solution at room temperature. The Fenton-photocatalytic activity of catalysts was tested by adding $0.05 \mathrm{M} \mathrm{H}_{2} \mathrm{O}_{2}$ into 


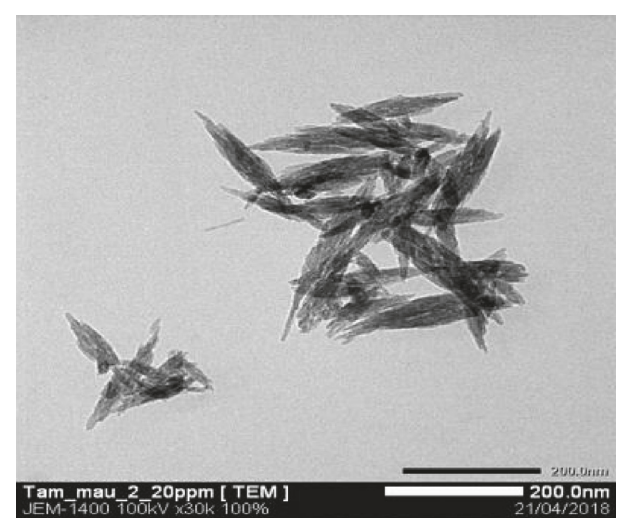

(a)

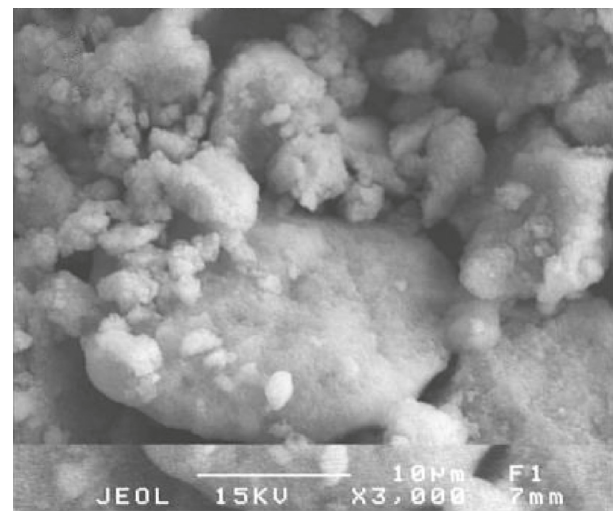

(c)

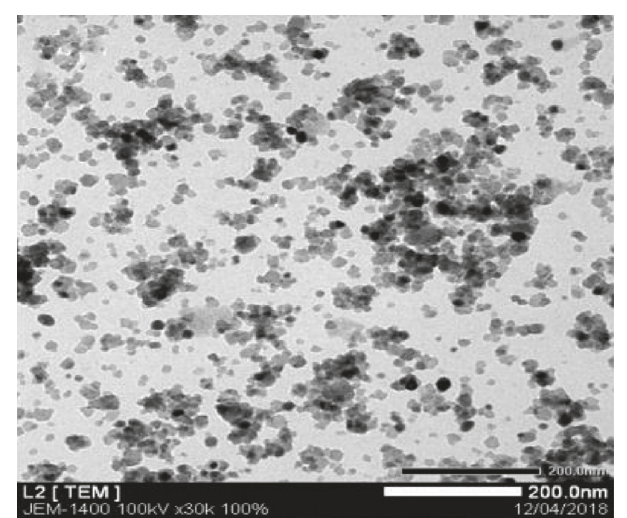

(b)

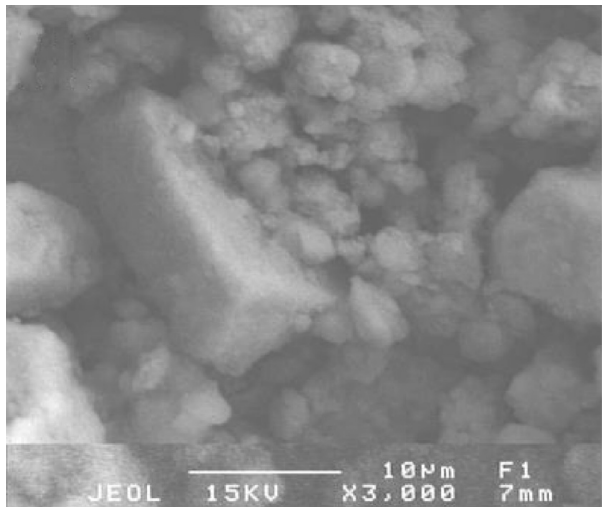

(d)

Figure 2: TEM and SEM images for HA $(a, c)$ and Zn-HA (b, d).

the $\mathrm{MB}$ solution. As seen in Figure 5, when $\mathrm{H}_{2} \mathrm{O}_{2}$ was absent, the removal efficiencies obtained for both $\mathrm{Zn}-\mathrm{HA}$ and $\mathrm{HA}$ were quite low as compared to those with the participation of $\mathrm{H}_{2} \mathrm{O}_{2}$. Besides, the maximum degradation efficiency of $\mathrm{Zn}$ $\mathrm{HA}$ was much higher than that of $\mathrm{HA}$ for both cases with presence of $\mathrm{H}_{2} \mathrm{O}_{2}$ and absence of $\mathrm{H}_{2} \mathrm{O}_{2}$ (Figure 5). Obviously, the removal process in the absence of $\mathrm{H}_{2} \mathrm{O}_{2}$ was controlled mainly by adsorption mechanism, and therefore, the smaller size of $\mathrm{Zn}$-HA helps it to take advantage over HA. In the presence of $\mathrm{H}_{2} \mathrm{O}_{2}$, along with adsorption mechanism, the Fenton-photocatalytic reactions could be activated and improved the degradation process. In this regard, the higher degradation efficiency of Zn-HA than that of HA indicated its stronger Fenton-photocatalytic potential. In other words, the presence of $\mathrm{Zn}$ could significantly improve the Fenton-photocatalytic ability of HA.

The photodegradation mechanism can be formulated as follows. Under visible light irradiation, electron/hole pairs were photogenerated in the catalyst (equation (2)). Then, photogenerated electrons could be trapped by $\mathrm{H}_{2} \mathrm{O}_{2}$, leading to the formation of $\mathrm{OH}$ (equation (3)) [31]. At the same time, $\mathrm{Zn}^{2+}$ ions after occupying electrons (equations (4)) were transformed into $\mathrm{Zn}$ which reacted with $\mathrm{H}_{2} \mathrm{O}_{2}$ to form $\mathrm{ZnO}$, a strong photocatalyst (equation (5)) [32]. During light irradiation, $\mathrm{ZnO}$ was capable of creating more electrons and holes (equation (6)), and therefore, the decomposition process of $\mathrm{H}_{2} \mathrm{O}_{2}$ to release $\mathrm{OH}$ will be accelerated due to the support of electrons (equation (8)). In addition, the generated electrons could also stimulate the formation of superoxide radicals through reactions with dissolved oxygen in the solution (equation (7)). Meanwhile, the holes could also contribute to the formation of $\mathrm{OH}$ when reacting with $\mathrm{H}_{2} \mathrm{O}$ and $\mathrm{OH}^{-}$ (equations (8) and (9)). Finally, $\mathrm{OH}$ and $\mathrm{O}_{2}{ }^{-}$will degrade $\mathrm{MB}$ molecules according to equations (10) and (11) [33].

$$
\begin{aligned}
& \mathrm{Zn}-\mathrm{HA}+h \nu \longrightarrow \mathrm{Zn}-\mathrm{HA}+e^{-}+h^{+} \\
& \mathrm{H}_{2} \mathrm{O}_{2}+e^{-} \longrightarrow \mathrm{OH}+\mathrm{OH}^{-} \\
& \mathrm{Zn}^{2+}+2 e^{-} \longrightarrow \mathrm{Zn} \\
& \mathrm{Zn}+\mathrm{H}_{2} \mathrm{O}_{2} \longrightarrow \mathrm{ZnO}+\mathrm{H}_{2} \mathrm{O} \\
& \mathrm{ZnO}+h \nu \longrightarrow e^{-}+h^{+} \\
& e^{-}+\mathrm{O}_{2} \longrightarrow \mathrm{O}_{2}{ }^{-} \\
& h^{+}+\mathrm{H}_{2} \mathrm{O} \longrightarrow \mathrm{H}^{+}+{ }^{\cdot} \text { OH } \\
& h^{+}+\mathrm{OH}^{-} \longrightarrow \text { OH }^{\cdot} \\
& \mathrm{OH}+\mathrm{MB}^{\longrightarrow} \text { degradation products } \\
& \mathrm{O}_{2}{ }^{-}+\mathrm{MB}^{\longrightarrow} \text { degradation products }
\end{aligned}
$$




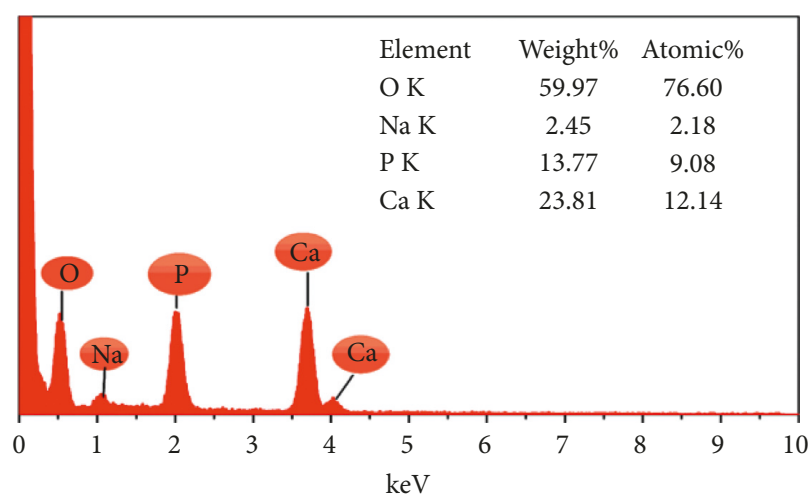

(a)

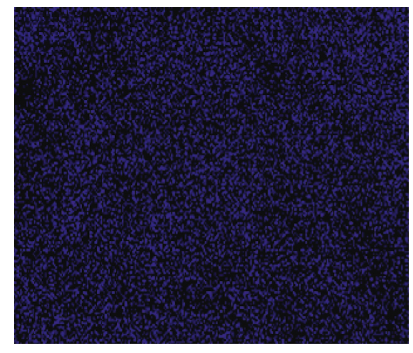

$\mathrm{Ca} \mathrm{Kal}$

(c)

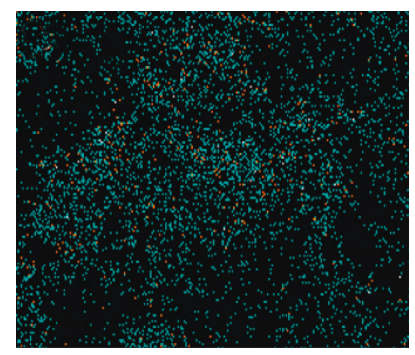

O Ka1

(e)

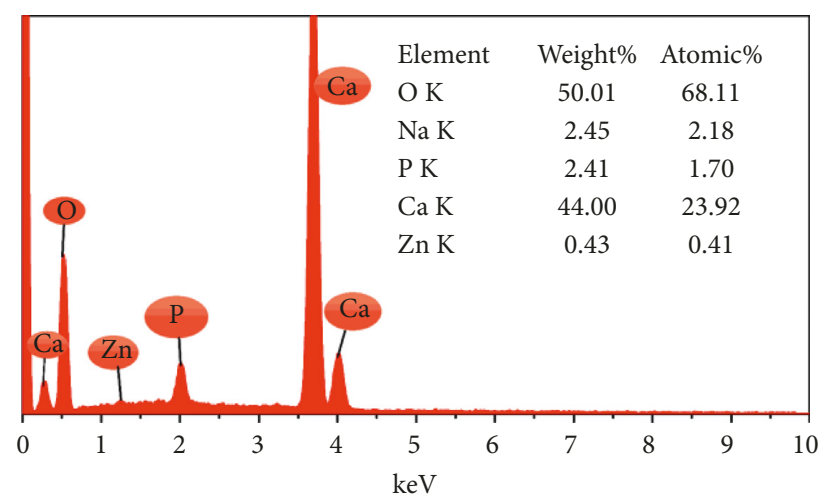

(b)

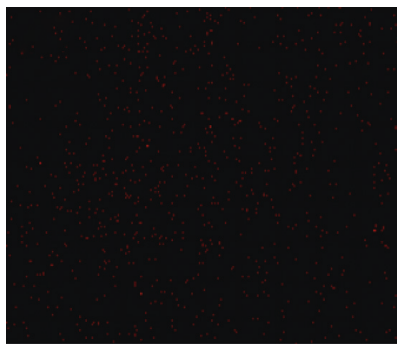

Zn Ka1

(d)

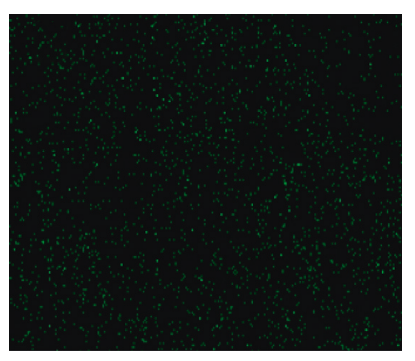

P Kal

(f)

Figure 3: EDX patterns of HA (a) and Zn-HA (b), and element distribution on Zn-HA surface for calcium (c), zinc (d), oxygen (e), and phosphorus (f).

Although the above results indicated the advantage of $\mathrm{Zn}$ in enhancing Fenton-photocatalytic activity of $\mathrm{Zn}-\mathrm{HA}$ over HA, the optimum content of $\mathrm{Zn}$ is needed to be determined. For this purpose, a comparative study on catalytic activity of $\mathrm{Zn}-\mathrm{HA}$ samples with different zinc substitution degrees under the same degradation conditions as mentioned. The results showed that the zinc substitution degree of 0.4 gave the highest degradation efficiency of $95 \%$ after a contact time of $30 \mathrm{~min}$ as shown in Figure 6. In this regard, the obtained value of 0.4 is reasonable and was chosen for further experiments.

\subsection{Influence of Experimental Conditions on MB Degradation}

3.3.1. Effect of $p H$. Effect of $\mathrm{pH}$ on degradation efficiency of $\mathrm{Zn}-\mathrm{HA}$ was studied in $\mathrm{pH}$ range from 4 to 10 using $0.1 \mathrm{~g}$ of $\mathrm{Zn}-\mathrm{HA}$ added into $100 \mathrm{~mL}$ solution of $50 \mathrm{mg} / \mathrm{L} \mathrm{MB}$ and
$0.05 \mathrm{M} \mathrm{H} \mathrm{H}_{2} \mathrm{O}_{2}$. The obtained results are presented in Figure 7(a). It is obviously seen that the degradation efficiency significantly increased with increasing solution $\mathrm{pH}$. This can be explained by the increased amount of $\mathrm{OH}^{-}$ groups, leading to rise in the amount of $\mathrm{OH}$ radicals generated through Fenton-oxidation mechanism, and therefore the degradation process was improved [13]. The fact that increasing $\mathrm{pH}$ greater than 10 does not make sense for practical applications since there is no economic benefit and the secondary pollutants could be generated at high $\mathrm{pH}$. In this regard, $\mathrm{pH}=10$ was chosen as an optimal $\mathrm{pH}$ for all catalytic experiments in this work.

3.3.2. Effect of Initial $M B$ Concentrations. Different initial $\mathrm{MB}$ concentrations of $20,30,50,80$, and $100 \mathrm{mg} / \mathrm{L}$ were used to evaluate their effect on degradation efficiency of $\mathrm{Zn}$ $\mathrm{HA}$ catalyst under $\mathrm{pH}$ of 10 , catalyst dosage of $0.1 \mathrm{~g}$, and 


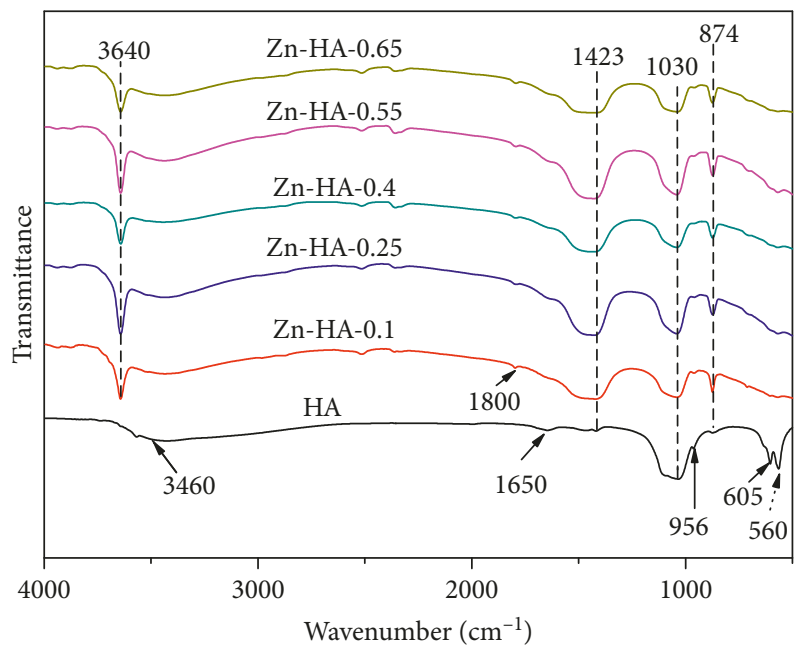

FIGURE 4: FTIR spectra for HA and Zn-HA samples with different Zn content.

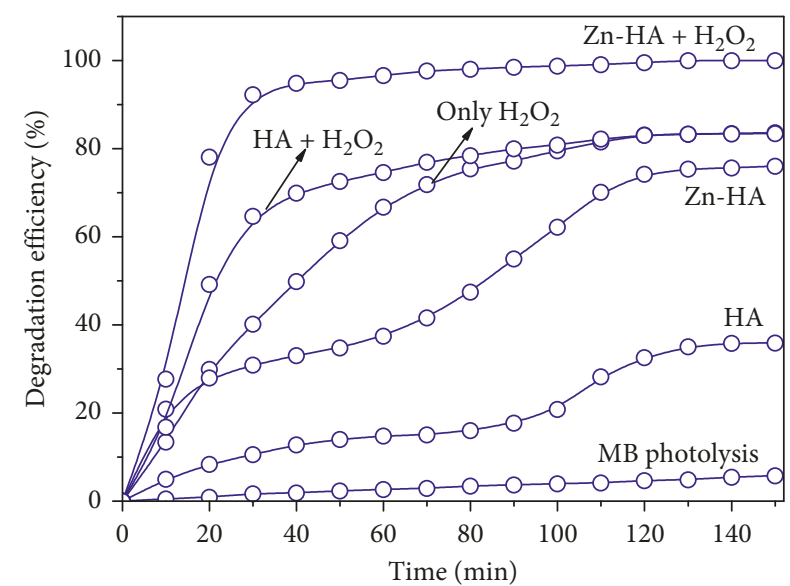

FIgUre 5: Comparative study on catalytic activity of the HA and $\mathrm{Zn}-\mathrm{HA}$ for degradation of MB.

$\mathrm{H}_{2} \mathrm{O}_{2}$ dosage of $0.05 \mathrm{M}$ at room temperature. Based on the obtained results, the optimal initial $\mathrm{MB}$ concentration was determined as $30 \mathrm{mg} / \mathrm{L}$ (Figure $7(\mathrm{~b})$ ). At concentrations higher than $30 \mathrm{mg} / \mathrm{L}$, the reduction of degradation efficiency was observed. The anomaly could be related to the formation of a layer of $\mathrm{MB}$ molecules accumulated on $\mathrm{Zn}$ $\mathrm{HA}$ surface at high $\mathrm{MB}$ concentrations, inhibiting light from entering $\mathrm{Zn}$ sites and therefore holding back the decolorization process [34].

3.3.3. Effect of $\mathrm{H}_{2} \mathrm{O}_{2}$ Concentration. The study was carried out using different initial $\mathrm{H}_{2} \mathrm{O}_{2}$ concentrations of 0.01 , $0.03,0.05$, and $0.10 \mathrm{M}$ under the established above optimal conditions. According to the results shown in Figure $7(\mathrm{c})$, the initial $\mathrm{H}_{2} \mathrm{O}_{2}$ concentration of $0.05 \mathrm{M}$ is optimal for degradation of $\mathrm{MB}$ using $\mathrm{Zn}-\mathrm{HA}$. The deviation of initial $\mathrm{H}_{2} \mathrm{O}_{2}$ concentration from $0.05 \mathrm{M}$ did not improve degradation process. It is obviously seen that at $\mathrm{H}_{2} \mathrm{O}_{2}$ concentrations lower $0.05 \mathrm{M}$, the reduction of

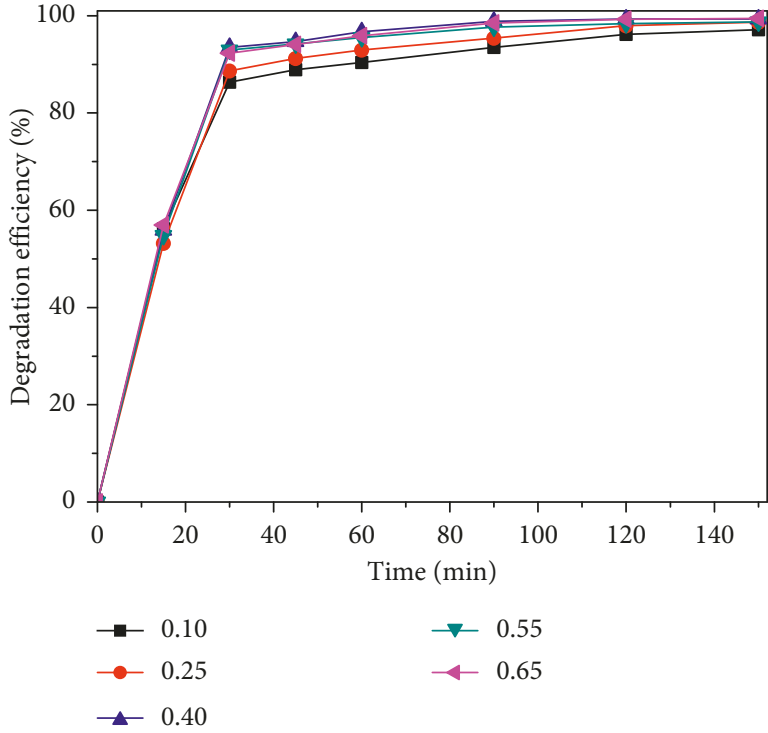

Figure 6: Comparative study on catalytic activity of Zn-HA samples with different zinc substitution degrees.

degradation efficiency could be associated with the decrease in the number of generated $\mathrm{OH}$ radicals. Meanwhile, at $\mathrm{H}_{2} \mathrm{O}_{2}$ concentrations greater than $0.05 \mathrm{M}$, the degradation efficiency did not increase (Figure $7(\mathrm{c})$ ), probably, due to the generation of perhydroxyl radicals caused by the combination of extra $\mathrm{H}_{2} \mathrm{O}_{2}$ dosage with hydroxyl radicals [35].

3.4. Stability and Reusability of Catalyst. The stability and reusability of a catalyst are essential for its practical applications. For Zn-HA catalyst, the recycling tests were carried out under optimal conditions in five continuous cycles. The results shown in Figure 8(a) indicated that the catalytic potential of $\mathrm{Zn}-\mathrm{HA}$ towards $\mathrm{MB}$ was well maintained with a slight reduction of degradation efficiency from $100 \%$ to $96.5 \%$ after five continuous cycles. Besides, the XRD pattern of $\mathrm{Zn}$-HA after the fifth degradation cycle contained almost all characteristic peaks (Figure 8(b)), demonstrating high stability of composite structure during degradation process.

\section{Conclusions}

In this study, the nanosized Zn-HA was successfully synthesized and applied as a heterogeneous photo-Fenton-like catalyst for $\mathrm{MB}$ degradation under optimal conditions of $\mathrm{pH}=10, \mathrm{H}_{2} \mathrm{O}_{2}$ dosage of $0.05 \mathrm{M}$, and $\mathrm{MB}$ concentration of $30 \mathrm{mg} / \mathrm{L}$ for a contact time of $120 \mathrm{~min}$. Besides, the zinc substitution degree of 0.4 is optimal to improve the photocatalytic activity of the catalyst. The recycling study demonstrated a good maintenance of degradation ability and high stability of catalyst structure in a long-term degradation process. Overall, the positive results suggested that the synthesized catalyst can be expected as a promising heterogeneous photocatalyst for degradation of $\mathrm{MB}$ in industrial wastewater. 

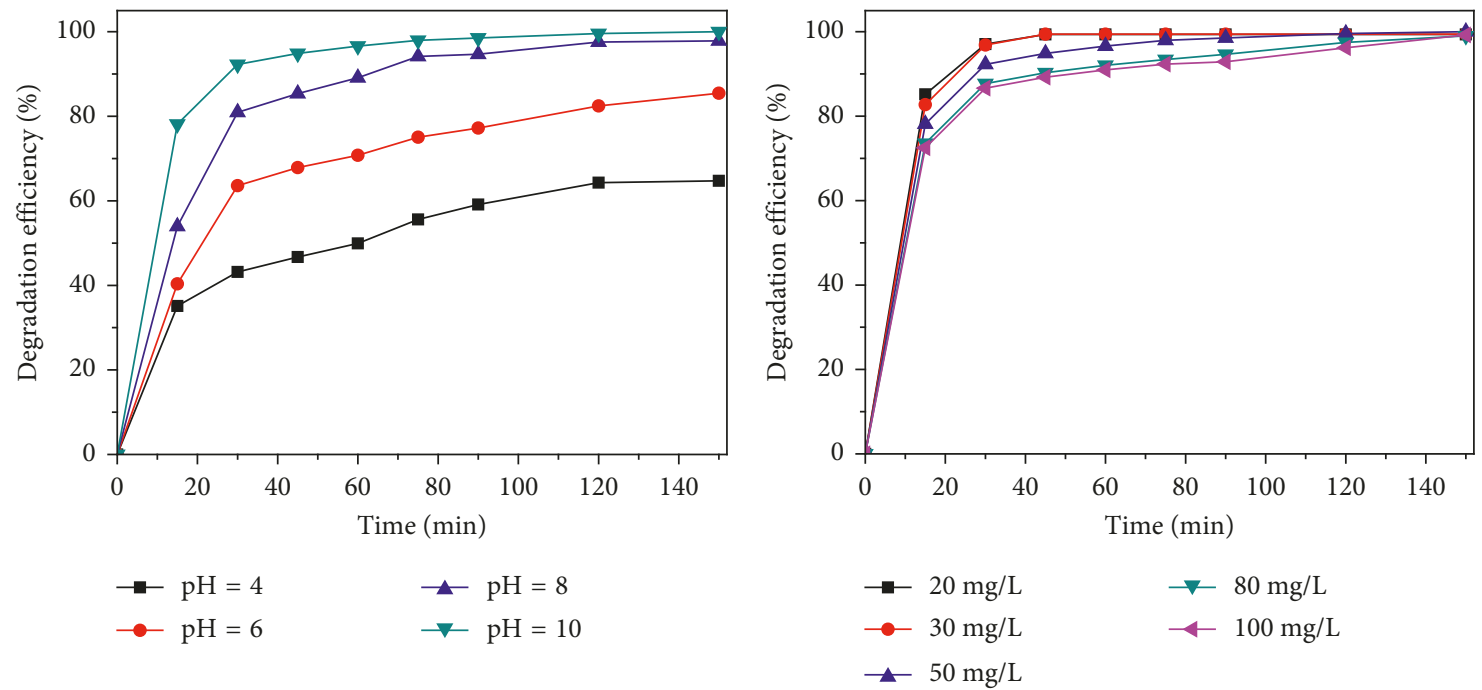

(a)

(b)

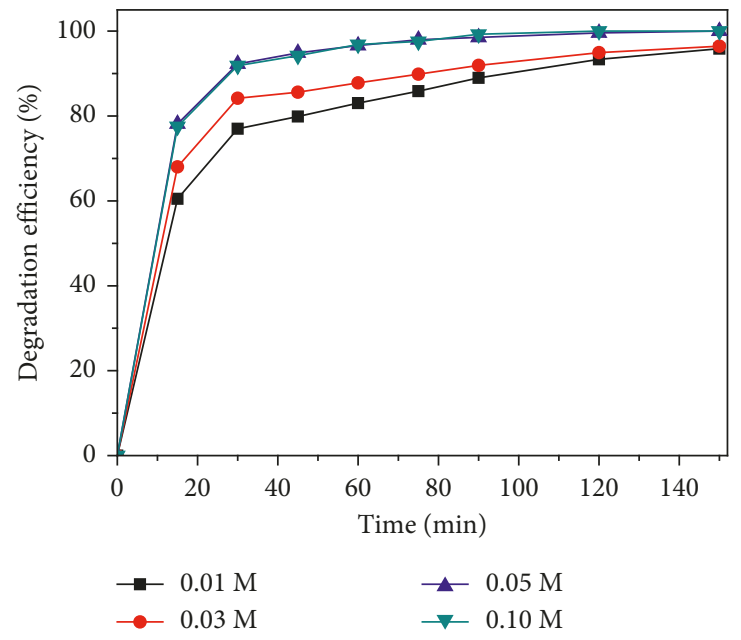

(c)

FIGURE 7: Effects of degradation conditions on degradation efficiency of $\mathrm{Zn}-\mathrm{HA}$ sample. (a) pH. (b) Initial MB concentration. (c) Initial $\mathrm{H}_{2} \mathrm{O}_{2}$ concentration.

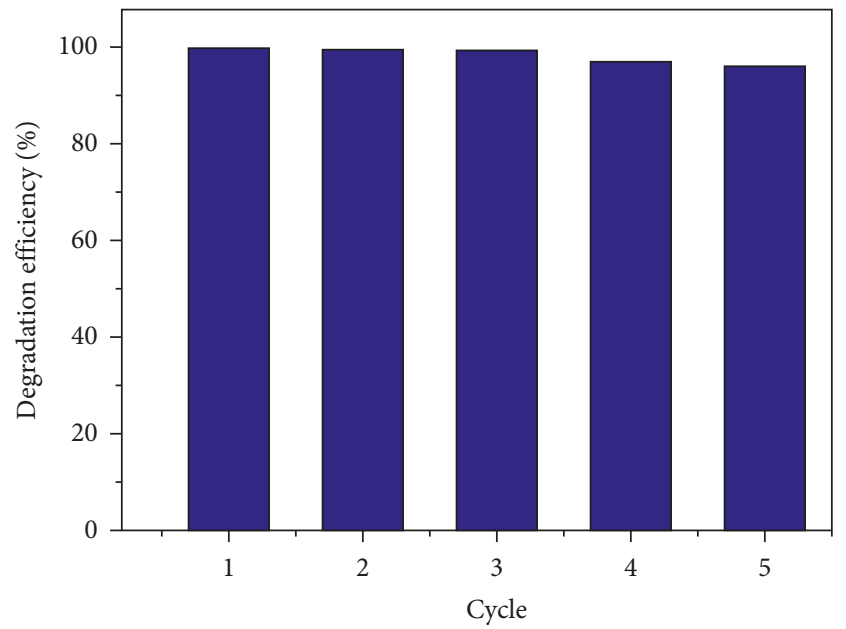

(a)

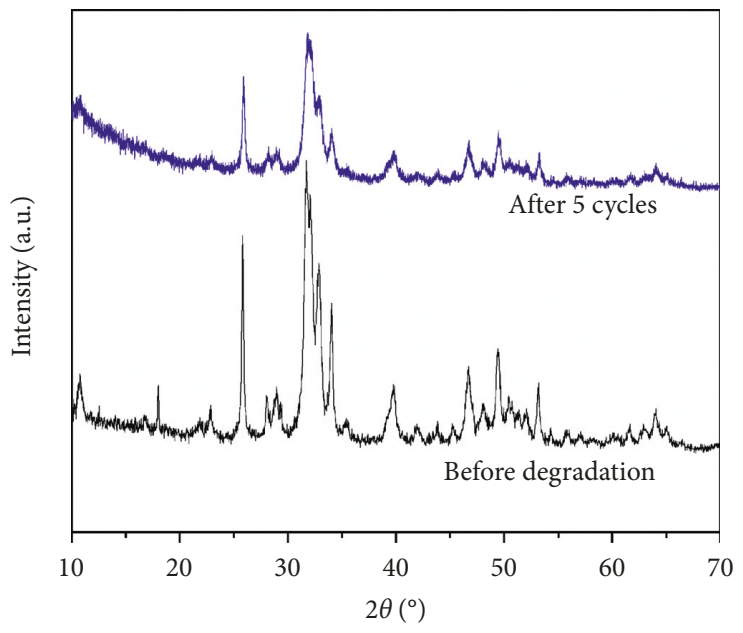

(b)

FIGURE 8: Degradation efficiency reduction (a) and the change of XRD pattern (b) of Zn-HA after for continuous cycles. 


\section{Data Availability}

The all data used to support the findings of this study are included within the article.

\section{Conflicts of Interest}

The authors declare that they have no conflicts of interest.

\section{Acknowledgments}

The authors acknowledge the Industrial University of Ho Chi Minh City, Vietnam, for supporting this work (Funding No. 184.HHO5).

\section{References}

[1] V. Katheresan, J. Kansedo, and S. Y. Lau, "Efficiency of various recent wastewater dye removal methods: a review," Journal of Environmental Chemical Engineering, vol. 6, no. 4, pp. 4676-4697, 2018.

[2] H. Mittal, S. M. Alhassan, and S. S. Ray, "Efficient organic dye removal from wastewater by magnetic carbonaceous adsorbent prepared from corn starch," Journal of Environmental Chemical Engineering, vol. 6, no. 6, pp. 7119-7131, 2018.

[3] T. T. T. Tran, V. D. Doan, T. T. T. Ho, V. T. Le, and H. T. Nguyen, "Novel of $\mathrm{TiO}_{2} / \mathrm{Ag}_{3} \mathrm{PO}_{4}$ /bentonite composite photocatalyst: preparation, characterization, and application for degradation of methylene blue in aqueous solution," Environmental Engineering Science, vol. 36, no. 1, pp. 71-80, 2019.

[4] K.-T. Chung, "Azo dyes and human health: a review," Journal of Environmental Science and Health, Part C, vol. 34, no. 4, pp. 233-261, 2016.

[5] L. Leo, C. Loong, X. L. Ho, M. F. B. Raman, M. Y. T. Suan, and W. M. Loke, "Occurrence of azo food dyes and their effects on cellular inflammatory responses," Nutrition, vol. 46, pp. 3640, 2018

[6] L. Tang, J. Yu, Y. Pang et al., "Sustainable efficient adsorbent: alkali-acid modified magnetic biochar derived from sewage sludge for aqueous organic contaminant removal," Chemical Engineering Journal, vol. 336, pp. 160-169, 2018.

[7] M. Wawrzkiewicz and Z. Hubicki, "Anion exchange resins as effective sorbents for removal of acid, reactive, and direct dyes from textile wastewaters," in Ion Exchange-Studies and Applications, IntechOpen, London, UK, 2015.

[8] M. T. Yagub, T. K. Sen, S. Afroze, and H. M. Ang, "Dye and its removal from aqueous solution by adsorption: a review," Advances in Colloid and Interface Science, vol. 209, pp. 172184, 2014.

[9] P. Zhao, S. Li, J. Zhao, C. M. Gaspar, and X. Weng, "Training by visual identification and writing leads to different visual word expertise N170 effects in preliterate Chinese children," Developmental Cognitive Neuroscience, vol. 15, pp. 106-116, 2015.

[10] S. De Gisi, G. Lofrano, M. Grassi, and M. Notarnicola, "Characteristics and adsorption capacities of low-cost sorbents for wastewater treatment: a review," Sustainable Materials and Technologies, vol. 9, pp. 10-40, 2016.

[11] R. Ameta, A. K. Chohadia, A. Jain, and P. B. Punjabi, "Fenton and photo-fenton processes," in Advanced Oxidation Processes for Waste Water Treatment, S. C. Ameta and R. Ameta, Eds., pp. 49-87, Academic Press, Cambridge, MA, USA, 2018, ISBN 9780128104996.
[12] A. Mirzaei, Z. Chen, F. Haghighat, and L. Yerushalmi, "Removal of pharmaceuticals from water by homo/heterogonous Fenton-type processes-a review," Chemosphere, vol. 174, pp. 665-688, 2017.

[13] S. Kalal, A. Pandey, R. Ameta, and P. B. Punjabi, "Heterogeneous photo-Fenton-like catalysts $\mathrm{Cu}_{2} \mathrm{~V}_{2} \mathrm{O}_{7}$ and $\mathrm{Cr}_{2} \mathrm{~V}_{4} \mathrm{O}_{13}$ for an efficient removal of azo dye in water," Cogent Chemistry, vol. 2, no. 1, article 1143344, 2016.

[14] B. Palas, G. Ersöz, and S. Atalay, "Photo Fenton-like oxidation of Tartrazine under visible and UV light irradiation in the presence of $\mathrm{LaCuO}_{3}$ perovskite catalyst," Process Safety and Environmental Protection, vol. 111, pp. 270-282, 2017.

[15] Y. He, D. B. Jiang, D. Y. Jiang, J. Chen, and Y. X. Zhang, "Evaluation of $\mathrm{MnO}_{2}$-templated iron oxide-coated diatomites for their catalytic performance in heterogeneous photo Fenton-like system," Journal of Hazardous Materials, vol. 344, pp. 230-240, 2018.

[16] M. S. Vasilyeva, V. S. Rudnev, A. A. Zvereva et al., " $\mathrm{FeOx}, \mathrm{SiO}_{2}, \mathrm{TiO}_{2} / \mathrm{Ti}$ composites prepared using plasma electrolytic oxidation as photo-Fenton-like catalysts for phenol degradation," Journal of Photochemistry and Photobiology A: Chemistry, vol. 356, pp. 38-45, 2018.

[17] Y. Zhu, R. Zhu, L. Yan et al., "Visible-light Ag/AgBr/ ferrihydrite catalyst with enhanced heterogeneous photoFenton reactivity via electron transfer from $\mathrm{Ag} / \mathrm{AgBr}$ to ferrihydrite," Applied Catalysis B: Environmental, vol. 239, pp. 280-289, 2018.

[18] A. Zhang, L. Zhu, and Z. Nan, "Ni-doped $\mathrm{Fe}_{3} \mathrm{O}_{4}$ nanoparticles coupled with $\mathrm{SnS}_{2}$ nanosheets as $0 \mathrm{D} / 2 \mathrm{D}$ heterogeneous catalyst for photo-Fenton reaction," Materials Chemistry and Physics, vol. 224, pp. 156-168, 2019.

[19] L. Yu, J. Chen, Z. Liang, W. Xu, L. Chen, and D. Ye, "Degradation of phenol using $\mathrm{Fe}_{3} \mathrm{O}_{4}$-GO nanocomposite as a heterogeneous photo-Fenton catalyst," Separation and Purification Technology, vol. 171, pp. 80-87, 2016.

[20] C. Liang, Y. Liu, K. Li et al., "Heterogeneous photo-Fenton degradation of organic pollutants with amorphous Fe-Znoxide/hydrochar under visible light irradiation," Separation and Purification Technology, vol. 188, pp. 105-111, 2017.

[21] V. T. Le, V. D. Doan, D. D. Nguyen et al., "A novel crosslinked magnetic hydroxyapatite/chitosan composite: preparation, characterization, and application for $\mathrm{Ni}(\mathrm{II})$ ion removal from aqueous solution," Water, Air, \& Soil Pollution, vol. 229, no. 3, p. 101, 2018.

[22] L. V. Thuan, D. V. Dat, P. C. Nguyen, and M. A. Trubitsyn, "Synthesis of calcium-deficient carbonated hydroxyapatite as promising sorbent for removal of lead ions," Journal of Nano Research, vol. 45, pp. 124-133, 2017.

[23] W. Liu, G. Qian, B. Zhang, L. Liu, and H. Liu, "Facile synthesis of spherical nano hydroxyapatite and its application in photocatalytic degradation of methyl orange dye under UV irradiation," Materials Letters, vol. 178, pp. 15-17, 2016.

[24] S. Valizadeh, M. H. Rasoulifard, and M. S. S. Dorraji, "Modified $\mathrm{Fe}_{3} \mathrm{O}_{4}$-hydroxyapatite nanocomposites as heterogeneous catalysts in three UV, Vis and Fenton like degradation systems," Applied Surface Science, vol. 319, pp. 358-366, 2014.

[25] J. H. Shariffuddin, M. I. Jones, and D. A. Patterson, "Greener photocatalysts: hydroxyapatite derived from waste mussel shells for the photocatalytic degradation of a model azo dye wastewater," Chemical Engineering Research and Design, vol. 91, no. 9, pp. 1693-1704, 2013.

[26] A. Fihri, C. Len, R. S. Varma, and A. Solhy, "Hydroxyapatite: a review of syntheses, structure and applications in 
heterogeneous catalysis," Coordination Chemistry Reviews, vol. 347, pp. 48-76, 2017.

[27] M. Ferri, S. Campisi, M. Scavini, C. Evangelisti, P. Carniti, and A. Gervasini, "In-depth study of the mechanism of heavy metal trapping on the surface of hydroxyapatite," Applied Surface Science, vol. 475, pp. 397-409, 2019.

[28] E. S. Thian, T. Konishi, Y. Kawanobe et al., "Zinc-substituted hydroxyapatite: a biomaterial with enhanced bioactivity and antibacterial properties," Journal of Materials Science: Materials in Medicine, vol. 24, no. 2, pp. 437-445, 2013.

[29] T. G. Peñaflor Galindo, T. Kataoka, S. Fujii, M. Okuda, and M. Tagaya, "Preparation of nanocrystalline zinc-substituted hydroxyapatite films and their biological properties," Colloid and Interface Science Communications, vol. 10-11, pp. 15-19, 2016.

[30] I. Karacan, D. Senturk, F. N. Oktar et al., "Structural and characterisation analysis of zinc-substituted hydroxyapatite with wet chemical precipitation method," International Journal of Nano and Biomaterials, vol. 6, no. 3-4, pp. 188-204, 2016.

[31] X. S. Nguyen, G. Zhang, and X. Yang, "Mesocrystalline Zndoped $\mathrm{Fe}_{3} \mathrm{O}_{4}$ hollow submicrospheres: formation mechanism and enhanced photo-fenton catalytic performance," ACS Applied Materials \& Interfaces, vol. 9, no. 10, pp. 8900-8909, 2017.

[32] K. M. Lee, C. W. Lai, K. S. Ngai, and J. C. Juan, "Recent developments of zinc oxide based photocatalyst in water treatment technology: a review," Water Research, vol. 88, pp. 428-448, 2016.

[33] W. Li, G. Wang, C. Chen, J. Liao, and Z. Li, "Enhanced visible light photocatalytic activity of $\mathrm{ZnO}$ nanowires doped with $\mathrm{Mn}^{2+}$ and $\mathrm{Co}^{2+}$ ions," Nanomaterials, vol. 7, no. 1, p. 20, 2017.

[34] F. Ji, C. Li, J. Zhang, and L. Deng, "Efficient decolorization of dye pollutants with $\mathrm{LiFe}\left(\mathrm{WO}_{4}\right)^{2}$ as a reusable heterogeneous Fenton-like catalyst," Desalination, vol. 269, no. 1-3, pp. 284-290, 2011.

[35] S. Xavier, R. Gandhimathi, P. V. Nidheesh, and S. T. Ramesh, "Comparison of homogeneous and heterogeneous Fenton processes for the removal of reactive dye Magenta MB from aqueous solution," Desalination and Water Treatment, vol. 53, no. 1, pp. 109-118, 2015. 


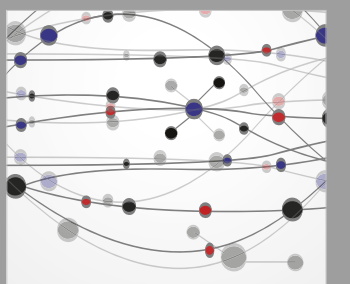

The Scientific World Journal
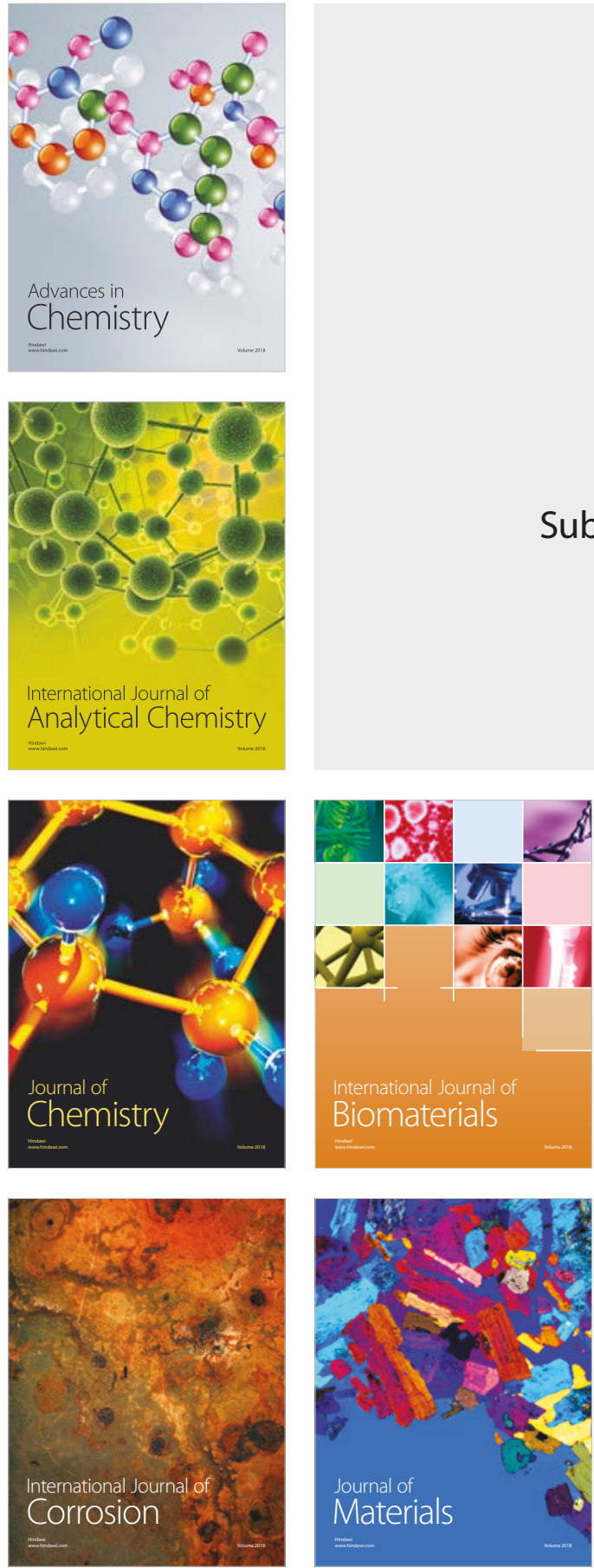

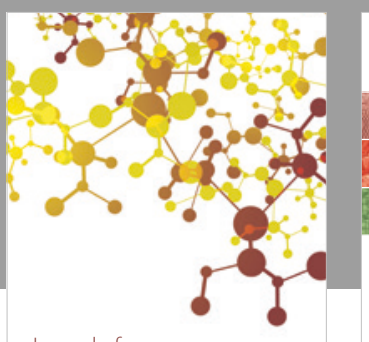

Journal of

Applied Chemistry
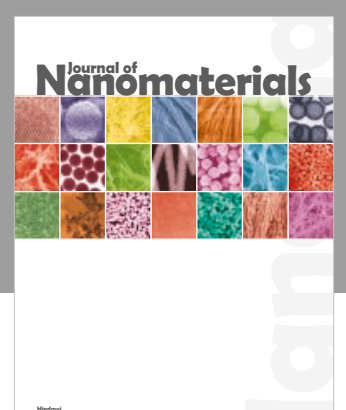

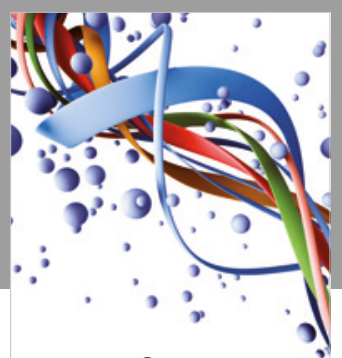

Scientifica

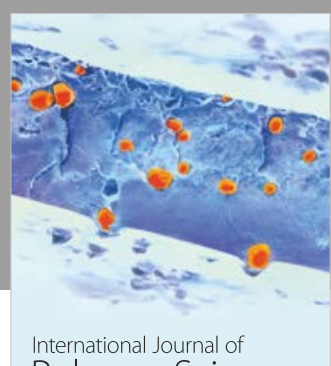

Polymer Science

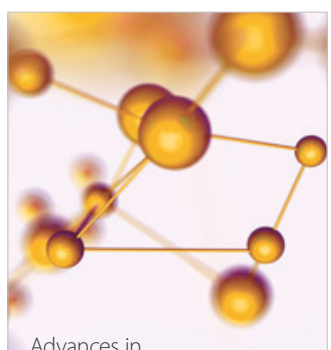

Physical Chemistry
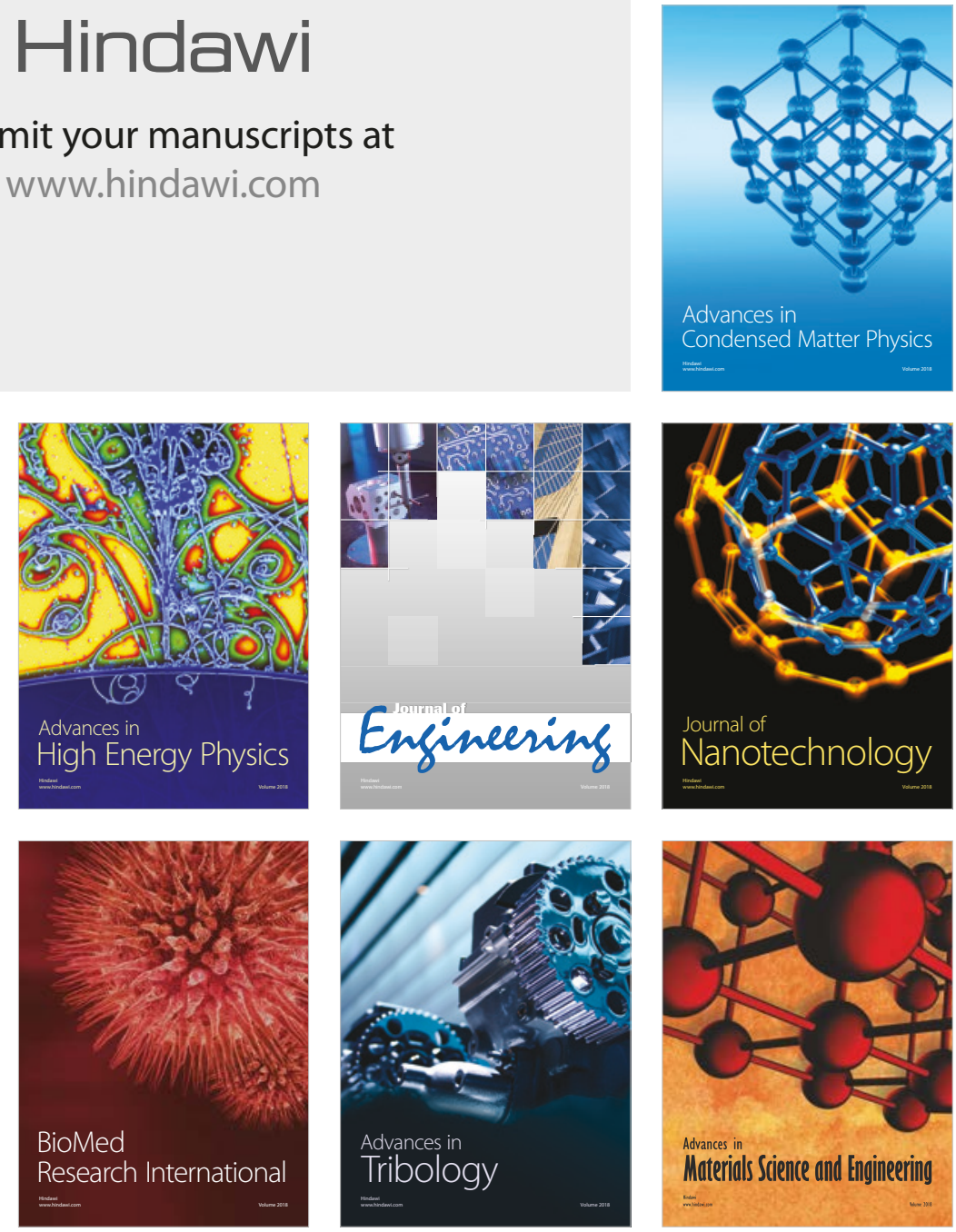